\title{
Methodology of Risk Analysis and Reclamation of Dangerous Technogenic Objects
}

\author{
Aleksey Koshelev, Elena Tikhomirova, Olga Atamanova \\ Yuri Gagarin State Technical University of Saratov, Saratov, Russia
}

doi: https://doi.org/10.21467/abstracts.93.13

\begin{abstract}
A B S T RA C T
Production facilities are one of the most dangerous man-made sources of impact on humans and the environment. This is due to the systematic release of pollutants into the air and the discharge of a significant amount of waste, including toxic waste, into reservoirs and soil. Identification of cause-and-effect relationships between environmental pollution with toxic chemicals and possible changes in human health is one of the urgent tasks of modern science. In the world practice, the methodology of risk analysis of the impact of pollution of environmental components on the health of the population has been actively used to solve this problem over the past decades.

The risk analysis methodology includes three elements: risk assessment, risk management, and risk awareness, which are interrelated. In relation to dangerous man-made objects, health risk assessment is the process of determining the risk of adverse effects in humans caused by exposure to toxic chemicals. The term toxic chemical substances (TCS) refers to those substances that, in contact with living organisms in certain environmental conditions and in a certain amount, can have an adverse effect on living organisms, up to death. Risk management is a logical extension of risk assessment, and is a process of making technical, political, legislative and regulatory decisions aimed at eliminating or significantly reducing the risk to public health. The third element of the risk analysis methodology is risk awareness - a process that involves informing all stakeholders about the risk.

All three elements of risk analysis are interrelated and only their combination allows not only to identify existing problems, develop ways to solve them, but also to create conditions for the practical implementation of these solutions. Hazard identification of the risk analysis in the Russian Federation is carried out according to the priority chemicals presented in the table.
\end{abstract}

Table - Priority of components of TOC pollution

\begin{tabular}{|l|l|}
\hline \multicolumn{1}{|c|}{ The hazard class } & \multicolumn{1}{|c|}{ Chemical element or compound } \\
\hline \hline I (highly dangerous) & $\begin{array}{l}\text { Arsenic, cadmium, mercury, lead, selenium, zinc, fluorine, Benz(a)pyrene, polychlorinated } \\
\text { biphenyls, organochlorine pesticides, dioxins }\end{array}$ \\
\hline II (dangerous) & Boron, cobalt, nickel, molybdenum, copper, antimony, chromium \\
\hline III (low-hazard) & Barium, vanadium, tungsten, manganese, strontium, acetophenone, petroleum products \\
\hline
\end{tabular}

The degree of danger of technogenic contaminated soils is determined in accordance with regulatory documents (SanPiN 2.1.7.1287-03 "Sanitary and epidemiological requirements for soil quality" and Guidelines MU 2.1.7.730-99 "Hygienic assessment of soil quality in populated areas"). In sanitary and epidemiological terms, soils are divided by the level of pollution: "clean", "acceptable", "moderately dangerous", "dangerous", "extremely dangerous". The scientific literature shows a high degree of correlation between the presence of soil in certain areas of the category "extremely dangerous" and the level of morbidity of the population, a high environmental threat to the environment. Therefore, the soil of the "extremely 
The Second Eurasian RISK-2020 Conference and Symposium

dangerous" category must be taken to a specialized landfill, or be sanitized (cleaned) with the release of a polluting component in situ (on site). Removal of a significant amount of contaminated soil (tens or hundreds of hectares) from a technogenic territory is complicated by two reasons:

- lack of landfills for toxic waste disposal in most regions of the Russian Federation;

- high cost of transporting toxic waste.

Russian legislation allows limited use of moderately dangerous and dangerous polluted soils on the reclaimed territory for filling pits and ditches with a layer of clean soil.

We have developed methods for reclamation of disturbed land objects of accumulated environmental damage in the past without removing land to landfills: a method for adsorption preparation of soil for cleaning it from heavy metals by phytoremediation [1], a method for reclamation of objects that have a negative effect on the environment [2], a method for reconstruction of an unauthorized landfill with its transformation into a landfill [3]. The latter method provides a technology for leaching (selective extraction) of THC from soils, which is illustrated below by the figure presented.

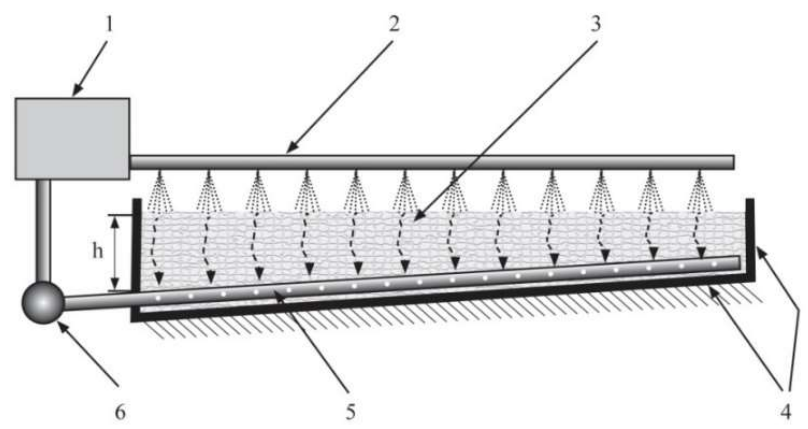

Drawing Scheme of soil and soil remediation by LEACHING: 1-water treatment station, 2-irrigation system, 3-sanitized soil, 4-waterproofing of the walls and bottom of the pit, 5-drainage system for collecting waste water, 6-pump for supplying waste water to the water treatment station.

Contaminated soil is laid in layers in a waterproofing pit; the height of the layer is determined by its filtering properties, depending on the nature and granulometric composition. An irrigation system is being assembled to ensure that the soil is evenly moistened. The water treatment station is located next to the pit in a temporary structure. Selection of the leach solution is carried out in the laboratory according to certain requirements developed by us. The proposed method is protected by the authors of the patent of the Russian Federation [3].

The work was carried out within the framework of the research Yuri Gagarin State Technical University of Saratov (2012-2014) "Improvement of technologies for monitoring anthropogenic disturbed territories, prevention and elimination of their pollution".

\section{Reference}

1.Troyanovskaya E.S., Tikhomirova E.I., Koshelev A.V., Zamatyrina V.A. Russian Patent for invention No. 2692554 Method of adsorption preparation of soil for cleaning it from heavy metals by phytoremediation // Bulletin of inventions of the Russian Federation No. 22 of 25.06.2019.

2. Koshelev A.V., Tikhomirova E.I., IvashchenkoYu.G., Kosarev A.V., Zamatyrina V.A. Russian Patent for invention No. 2633397 Method of reclamation of objects that have a negative effect on the environment // Bulletin of inventions of the Russian Federation No. 29 of 12.10.2017

3. Koshelev A.V., Atamanova O.V., Tikhomirova E.I., Zamatyrina V.A. Russian Patent for invention No. 2697095 Method for reconstruction of an unauthorized landfill with its transformation into a landfill // Bulletin of inventions of the Russian Federation No. 23 of 12.08.2019. 